\title{
The strain seismograms of P- and S-waves of a local event recorded by four-gauge borehole strainmeter
}

\author{
Zehua Qiu $\cdot$ Shunliang Chi $\cdot$ Zhenming Wang $\cdot$ Seth Carpenter $\cdot$ \\ Lei Tang $\cdot$ Yanping Guo $\cdot$ Guang Yang
}

Received: 2 December 2014/Accepted: 24 April 2015/Published online: 10 June 2015

(C) The Author(s) 2015. This article is published with open access at Springerlink.com

\begin{abstract}
At a sampling rate of 100 samples per second, the YRY-4 four-gauge borehole strainmeters (FGBS) are capable of recording transient strains caused by seismic waves such as $\mathrm{P}$ and $\mathrm{S}$ waves or strain seismograms. At such a high sampling rate, data from the YRY-4 strainmeters demonstrate fairly satisfactory self-consistency. The strain tensor seismograms demonstrate the senses of motion of $\mathrm{P}$ waves, that is, the type of seismic wave travels in the direction of the maximum normal strain change. The observed strain patterns of $\mathrm{S}$ waves significantly differ from those of $\mathrm{P}$ waves and should contain information about the source mechanism. Spectrum analysis shows that the strain seismograms are consistent with conventional broadband seismograms from the same site.
\end{abstract}

Keywords Four-gauge borehole strainmeter (FGBS) . Strain seismogram $\cdot \mathrm{P}$ wave $\cdot \mathrm{S}$ wave $\cdot$ Self-consistency . Spectrum analysis

\footnotetext{
Z. Qiu ( $₫) \cdot$ L. Tang · Y. Guo

Institute of Crustal Dynamics, China Earthquake Administration,

Beijing 100085, China

e-mail: qzhbh@163.com

S. Chi

Earthquake Administration of Hebi,

Hebi 458000, He'nan Province, China

Z. Wang $\cdot$ S. Carpenter

Kentucky Geological Survey, University of Kentucky,

Lexington, KY 40506, USA

G. Yang

Guza Seismic Station, Earthquake Administration of Sichuan

Province, Kangding 626001, Sichuan Province, China
}

\section{Introduction}

Two-dimensional borehole tensor strainmeters have been well developed since the 1970s both in theory (Pan 1977; Su 1977; Gladwin and Hart 1985; Hart et al. 1996; Roeloffs 2010; Qiu et al. 2013) and in technique (Ouyang 1977; Gladwin 1984; Ishii 2001; Chi et al. 2009). Many such instruments have been deployed in countries such as China, the United States and Japan to monitor tectonic movements related to earthquakes, volcanoes, episodic tremors and slips, and other events (Linde et al. 1996; Qiu et al. 2007; Wang et al. 2008; Voight et al. 2010; Hodgkinson et al. 2010; Chardot et al. 2010; Qiu et al. 2011; Hawthorne and Rubin 2013).

Theoretically, seismic wave propagation in a continuous medium is governed by the stress-strain relationship (Timoshenko and Goodier 1951; Bullen 1963; Stein and Wysession 2003). Therefore, a tensor strainmeter may have some advantages for studying wave propagation over a conventional seismometer. To date, however, a systematic study on strain seismograph has not been carried out. A high-quality 2D strainmeter, the YRY-4 four-gauge borehole strainmeter (FGBS), has been successfully developed and deployed in China (Chi et al. 2009; Qiu et al. 2013). In the China Earthquake Administration's observatory, FGBS data are routinely sampled at a rate of one sample per minute. In recent years, however, experiments have shown that the FGBS is capable of working at a sampling rate as high as 100 samples per second, with good signal-to-noise ratio.

\section{Strain seismograms}

On March 17, 2008, a FGBS at the Guza site (Fig. 1) recorded a local earthquake of magnitude 3.5 in Sichuan, 


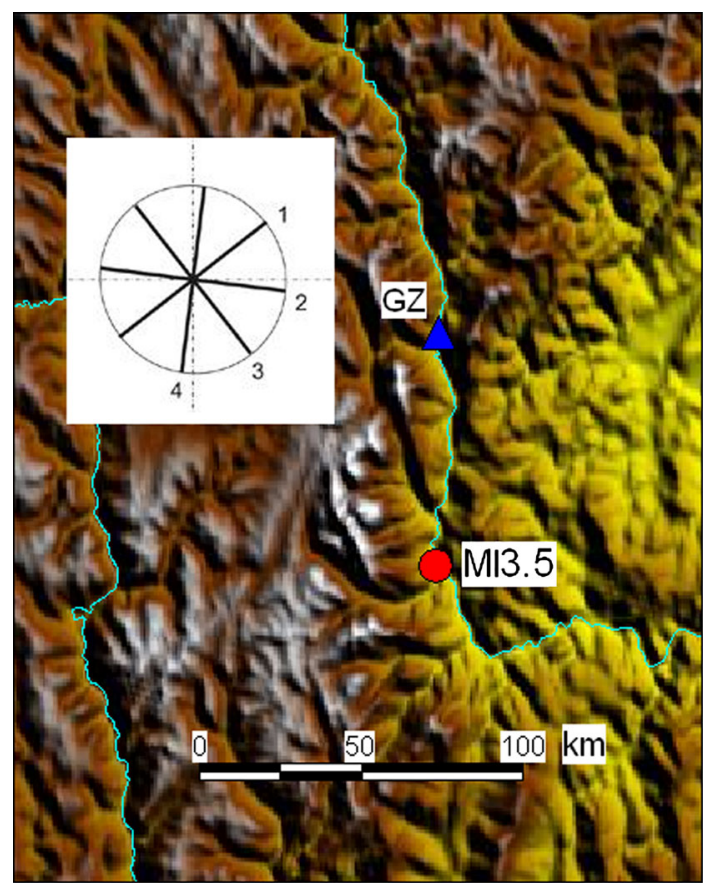

Fig. 1 Locations of the Guza site, and the ML3.5 earthquake. Directions of the four gauges in the FGBS are plotted

China, at 100 samples per second. The data from each component (Fig. 2) are high quality, with good signal-tonoise ratio.

In order to use the data of the four components to determine the strain tensor, we applied corrections based on relative in situ calibration, given in Qiu et al. (2013), to the raw time series, and the mean was removed from the data. Next, to satisfy a self-consistency criterion (Su 1977; Qiu et al. 2013), we verified equality of the sum of gauges S1 and S3 and the sum of gauges S2 and S4. As shown in Fig. 2, the seismograms of $\mathrm{S} 1+\mathrm{S} 3$ and $\mathrm{S} 2+\mathrm{S} 4$ are similar. We further examined self-consistency via plotting of $\mathrm{S} 1+\mathrm{S} 3$ versus $\mathrm{S} 2+\mathrm{S} 4$ by using the initial parts of the waveforms of the $P$ wave and the $\mathrm{S}$ wave, separately (Fig. 3). The lines fitting separately from $\mathrm{S} 1+\mathrm{S} 3$ and $\mathrm{S} 2+\mathrm{S} 4$ are close (Fig. 3), which demonstrates a high degree of self-consistency of the FGBS data, even for such a high sampling rate. Some data are not very well selfconsistent, especially for $\mathrm{P}$ wave. The reason is not yet known.

\section{Strain pattern of $\mathbf{P}$ waves}

Strain seismograms make it possible to plot deformation with time, while seismic waves pass through a site. When the data are self-consistent, the principal strain orientations are credible. Figure 4 shows the series of deformation patterns during the initial $0.24 \mathrm{~s}$ of the $\mathrm{P}$ wave (indicated in Fig. 2). The dotted ovals are drawn from a reference solid circle with exaggerated strains. Since the dominant period of the $\mathrm{P}$ wave here is nearly $0.2 \mathrm{~s}$, the process plotted is a little longer than one cycle of the deformational vibration.

By observing this series of plots, instant by instant, we can see that the axes of the ovals are mainly along two constant directions. One is nearly NS when the oval is larger than the reference circle; the other is nearly EW
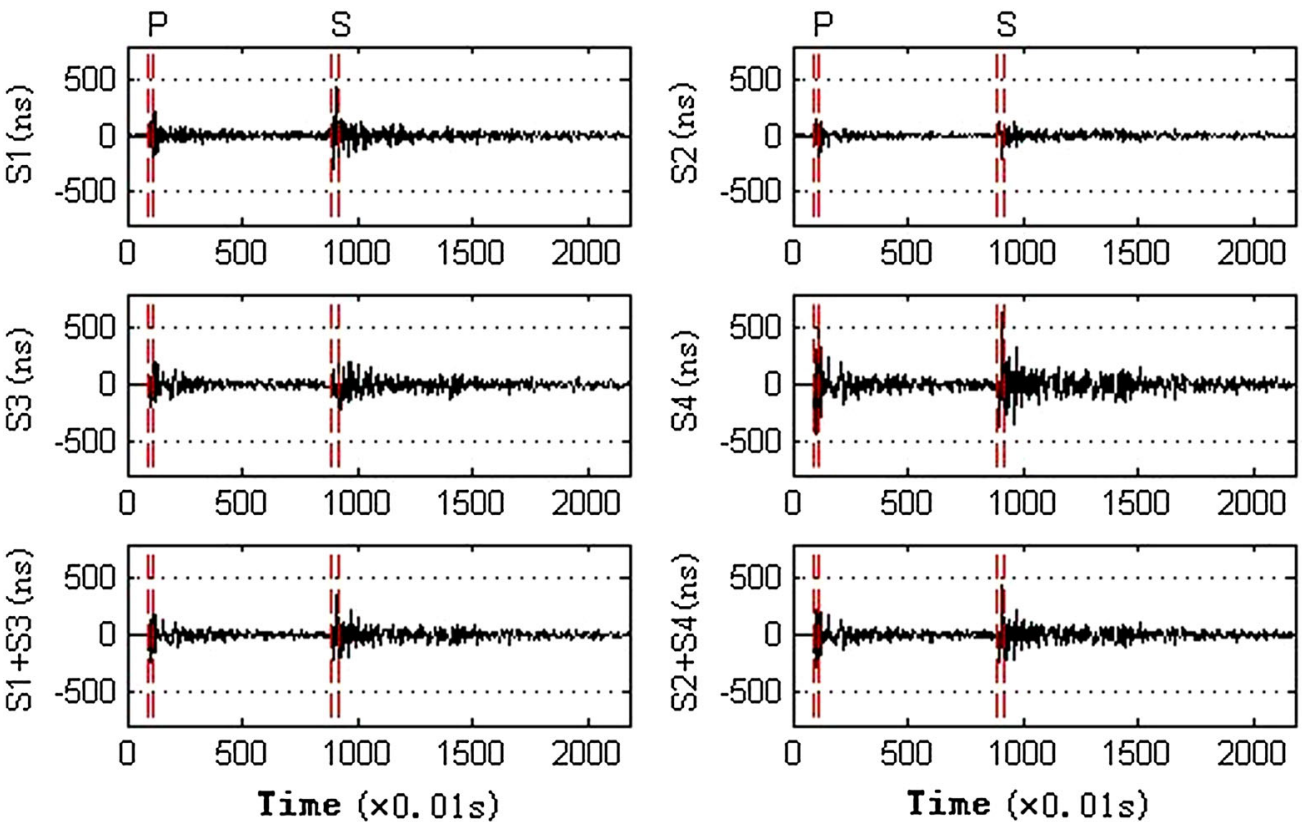

Fig. 2 Strain seismograms recorded at the site Guza from an ML3.5 earthquake of March 17, 2008. Dashed lines indicate the time intervals to be studied in detail for $\mathrm{P}$ waves and $\mathrm{S}$ waves 

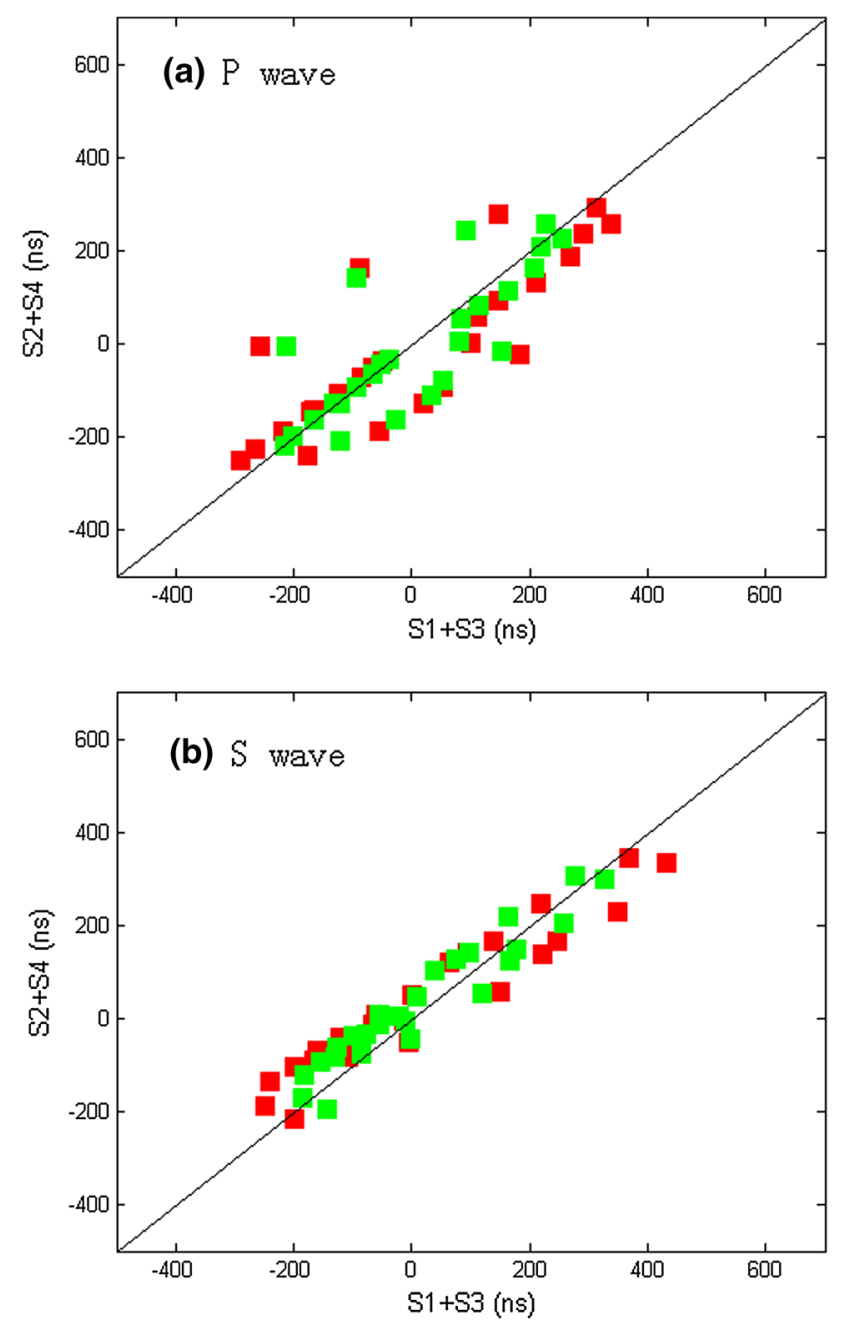

Fig. 3 Graphs of $\mathrm{S} 1+\mathrm{S} 3$ versus $\mathrm{S} 2+\mathrm{S} 4$. $\mathbf{a}$ and $\mathbf{b}$ are for the initial parts of the $\mathrm{P}$ wave and $\mathrm{S}$ wave, as indicated by dashed lines in Fig. 2 . Red stand for before correction, green after correction. Corrections in detail are given in Qiu et al. (2013)

when the oval is smaller than the circle. In fact, the NS axis changes much more in length than the EW axis. This can be clearly shown in Fig. 5 as all the ovals are stacked together.

Comparison of Figs. 1-5 shows that the most important feature of the $\mathrm{P}$ wave is that the diameter that changes most greatly coincides with the azimuth of the $\mathrm{P}$ wave's ray path, which here comes from the south.

The ovals actually indicate that there are shear strains in P wave. Qiu and Chi (2013) studied the graphs of S1-S3 and S2-S4 recorded by the YRY-4 of the identical event studied in this paper. The graphs show that $\mathrm{P}$ wave strain contains significant shear strain components, which are obviously bigger than possible error. According to the theory of seismology, $\mathrm{P}$ wave has been clarified to have no rotation but volumetric strain and shear strains.
1

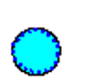

2

3

3

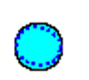

4

3

5

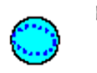

6

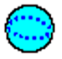

7

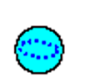

8

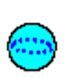

9

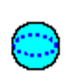

10

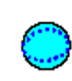

11

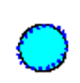

12

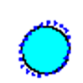

13

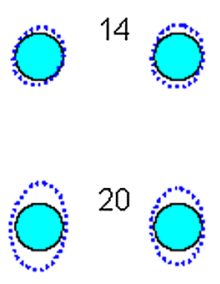

15<smiles>c1ccccc1</smiles>

16<smiles>[c]1ccccc1</smiles>

17<smiles>[c]1ccccc1</smiles>

18

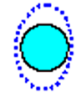

19

21

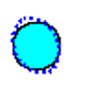

22

23

24
Fig. 4 Illustration of the recorded deformation for multiple instants at Guza while the initial part of the $\mathrm{P}$ wave passes through. The time interval is indicated in Fig. 2. The dotted ovals are drawn from a reference circle with exaggerated strains

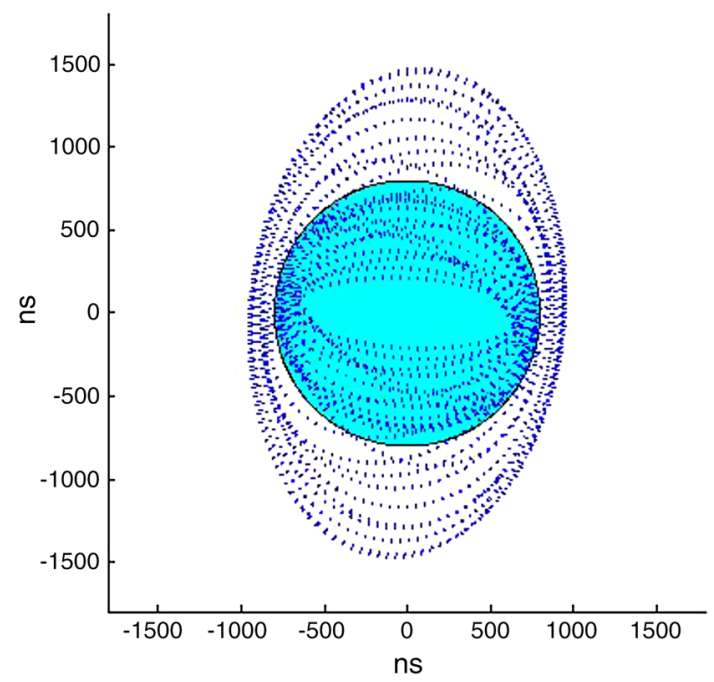

Fig. 5 Stacked ovals of the P wave deformations plotted in Fig. 4

\section{Strain pattern of $S$ wave}

Figures 6 and 7 show the series of deformation patterns during the initial part of the $\mathrm{S}$ wave (indicated in Fig. 2, total $0.24 \mathrm{~s}$ ). Dotted ovals are drawn in the same way as those in Fig. 5. The extension directions of the ovals are obviously different from those of the $\mathrm{P}$ wave. In this case, there are also two nearly constant directions: one is toward the northeast when the oval is larger; the other is toward the northwest when the oval is smaller.

The $\mathrm{S}$ wave is different from the $\mathrm{P}$ wave in terms of strain. Unlike the strain pattern of the $P$ wave, the strain pattern of the $\mathrm{S}$ wave does not indicate the location of the epicenter. 
1<smiles>c1ccccc1</smiles>
2

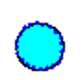
3<smiles>c1ccccc1</smiles>
4

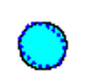

5

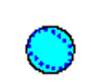

6

7

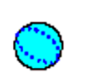

8

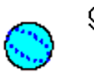

9

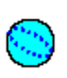

10

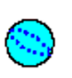

11

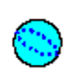

12

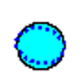

13

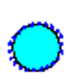

14

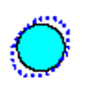

15

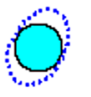

16

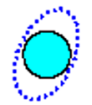

17

18

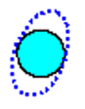

19

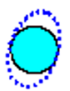

20

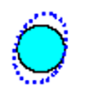

21

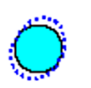

22

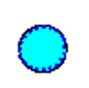

23

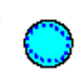

24

Fig. 6 Illustration of the recorded deformation for multiple instants at Guza while the initial part of the $\mathrm{S}$ wave passes through. The time interval is indicated in Fig. 2. The dotted ovals are drawn from a reference circle with exaggerated strains

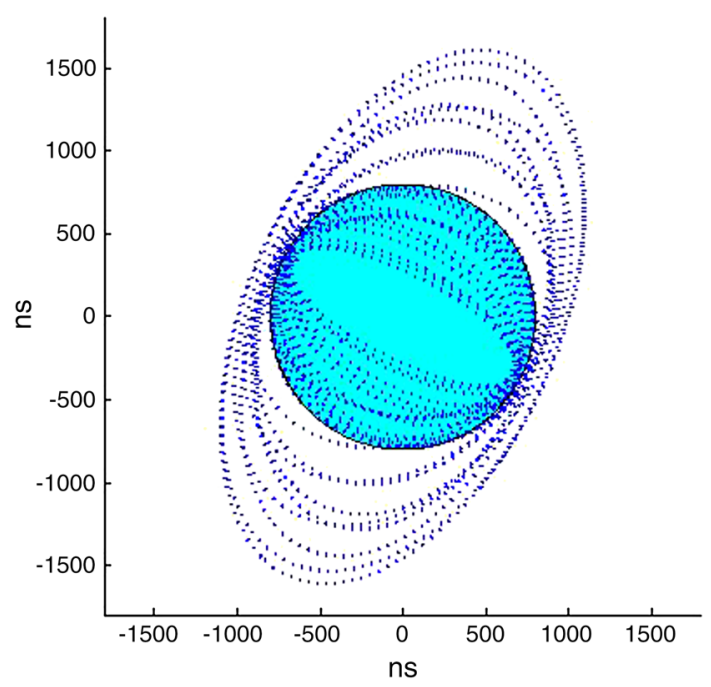

Fig. 7 Stacked ovals of the S wave deformations plotted in Fig. 6

\section{Comparison to conventional seismograms}

A tensor strainmeter is different from a conventional seismometer in that a conventional seismometer records the rigid, translational motion of a site, whereas a tensor strain seismograph observes the internal deformation at a site. The spectra of strain seismograms and conventional seismograms should be in agreement with each other, however, because they both are governed by wave propagation. Thus, strain seismograms and conventional seismograms should be comparable in terms of waveform and frequency content.

We compared the strain seismograms, rotated into cardinal directions according to Qiu et al. (2013), with seismograms recorded by a broadband CTS- 1 seismograph (flat response from $120 \mathrm{~s}$ to $20 \mathrm{~Hz}$ ), co-located at the Guza site for the March 17, 2008, ML3.5 event (Fig. 1). To the first order, the records strongly resemble each other (Fig. 8), though the instruments measure different physical quantities (strain versus velocity). Distinct $\mathrm{P}$ and $\mathrm{S}$ wave arrivals are visible in the strain and seismic waveforms: impulsive $\mathrm{P}$ and $\mathrm{SH}$ phases. In addition, we observed the same pattern of $\mathrm{P}$ and $\mathrm{S}$ phase polarities in the seismic data and the rotated strain data. To elaborate, $\mathrm{P}$ and $\mathrm{S}$ phase first motions observed on the north component of the seismic data $(\mathrm{VN})$ are both positive, and the first motions on the north component of the strain data are both negative. Likewise, the $\mathrm{P}$ and $\mathrm{S}$ phase first motions on the east component of the seismic data (VE) and the strain data are all positive. These observations suggest that the sense of motion correlates with the strain being either compressive or extensional.

We also compared the frequency content within each signal by estimating the power spectral densities (PSD) using Welch's method (Fig. 9). The smoothed spectral density estimates show well-defined peaks in the seismic data and the north and east strain data, $\varepsilon_{\mathrm{N}}$ and $\varepsilon_{\mathrm{E}}$, respectively, at $7 \mathrm{~Hz}$, corresponding to the $\mathrm{S}$ wave. All PSDs start falling off at around $13 \mathrm{~Hz}$, which corresponds to frequencies in the $\mathrm{P}$ wave, but show local maxima and minima at the same frequencies above $13 \mathrm{~Hz}$. There is an elevated response in the strain data to frequencies below $5 \mathrm{~Hz}$, compared to the seismic data. Power around $5 \mathrm{~Hz}$ is contained in both the $\mathrm{P}$ and $\mathrm{S}$ waves in the strain data and may reflect an increased sensitivity in the strainmeter at this frequency, perhaps a resonance.
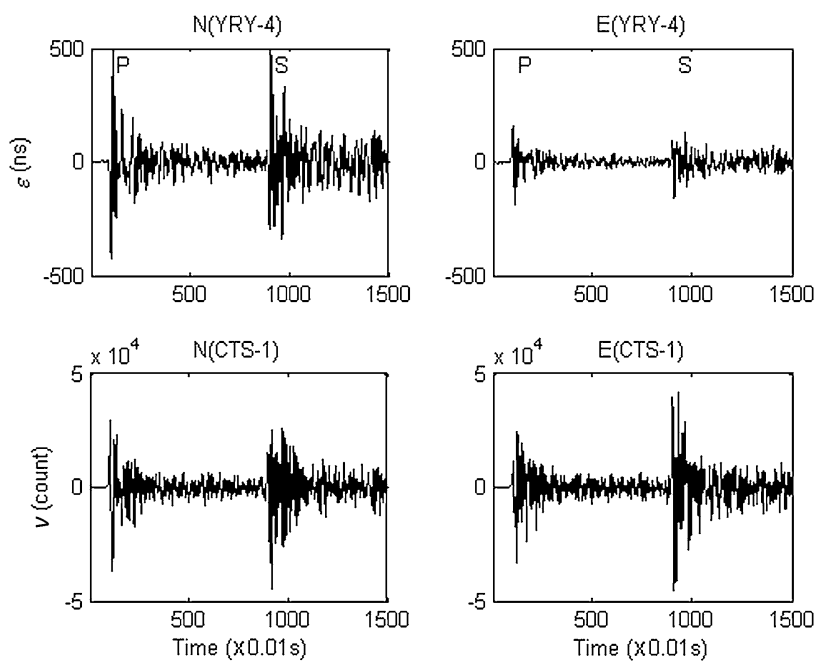

Fig. 8 Seismograms showing rotated nanostrain (top row) and velocity (bottom row; in counts) from the YRY-4 FGBS and the co-located CTS-1 seismograph, respectively, at station Guza. Northsouth nanostrain and seismic records are in the left column, and eastwest records are in the right column 


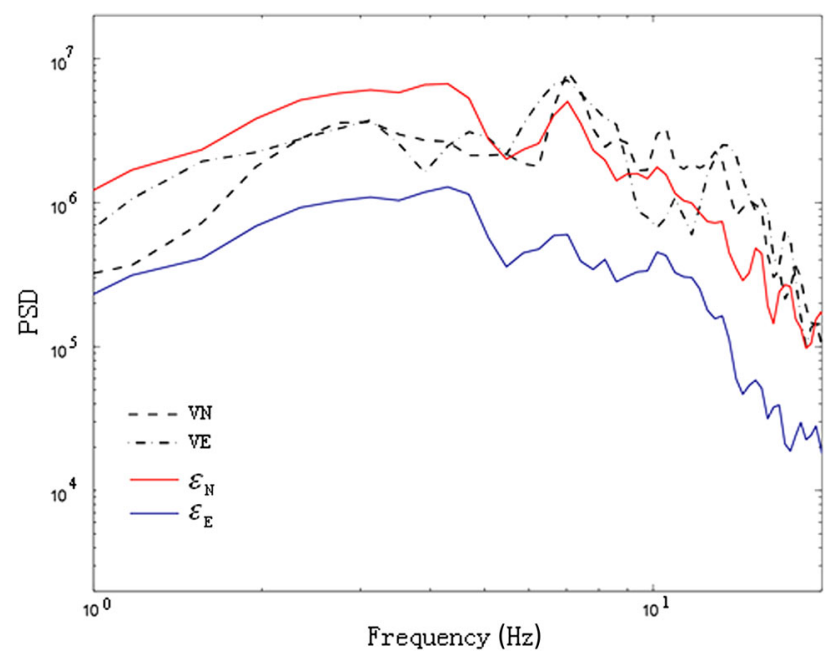

Fig. 9 Power spectral densities of the seismic (VN, VE) data and the rotated strain data $\left(\varepsilon_{\mathrm{N}}\right.$ and $\left.\varepsilon_{\mathrm{E}}\right)$. The units of the seismic PSDs are in counts ${ }^{2} / \mathrm{Hz}$, whereas the strain data PSDs are in nanostrain $2 / \mathrm{Hz}$. PSDs are estimated using Welch's method with 2 s windows, overlapping $50 \%$ to calculate each periodogram

These comparisons show that, to the first order, the records strongly resemble each other and suggest that the FGBS is sensitive to seismic waves at high frequencies. Further study is needed in order to determine if the FGBS could serve as a replacement for a seismometer.

\section{Conclusions}

At high sampling rates (i.e., 100 samples per second), the FGBS could be used as a strain seismometer. The gauges record consistent spectra across a broadband of frequencies and are comparable to those of a conventional seismometer. The data are self-consistent, even at a high sampling rate. The FGBS strain recordings verify that a $\mathrm{P}$ wave can be defined as the type of seismic wave that always travels in the direction of maximum normal strain. The strain patterns of $\mathrm{S}$ waves are different from those of $\mathrm{P}$ waves. Strain seismograms might have some advantages in comparison with conventional seismograms for studying $\mathrm{P}$ and $\mathrm{S}$ waves, as well as the seismic source.

This paper presents the observation result of the YRY-4 instrument at Guza of the ML3.5 event. It provides new meaningful information about body seismic waves. Among the tens of sites in China equipped with this kind of instrument, Guza is the first where the test of 100 samples per second is carried out. More observations are needed to better understand this phenomenon.

The relation between strain records and translation records needs to be further explained. Some studies have been published concerning this issue. For instance, Bouchon and Aki (1982) simulated the time histories of strain, tilt, and rotation in the vicinity of earthquake faults in comparison to translational velocities. However, it is about near-field situation where the distance from the epicenter is less than the length of the seismic fault. Therefore, it does not fit the observation which is done $70 \mathrm{~km}$ away from the small event whose seismic fault should be no more than a few kilometers in size.

Acknowledgments This study was supported by the Special Fund for Earthquake Research in the Public Interest (No. 201108009).

Open Access This article is distributed under the terms of the Creative Commons Attribution 4.0 International License (http:// creativecommons.org/licenses/by/4.0/), which permits unrestricted use, distribution, and reproduction in any medium, provided you give appropriate credit to the original author(s) and the source, provide a link to the Creative Commons license, and indicate if changes were made.

\section{References}

Barbour AJ, Agnew DC (2012) Detection of seismic signals using seismometers and strainmeters. Bull Seismol Soc Am 102:2484-2490

Bouchon M, Aki K (1982) Strain, tilt, and rotation associated with strong ground motion in the vicinity of earthquake faults. Bull Seismol Soc Am 72(5):1717-1738

Bullen KE (1963) An Introduction to the Theory of Seismology. Cambridge University Press, Cambridge, p 381

Chardot L, Voight B, Foroozan R, Sacks S, Linde A, Stewart R, Hidayat D, Clarke A, Elsworth D, Fournier N, Komorowski JC, Mattioli G, Sparks RSJ, Widiwijayanti C (2010) Explosion dynamics from strainmeter and microbarometer observations, Soufrière Hills volcano, Montserrat, 2008-2009. Geophys Res Lett 37:6

Chi SL, Chi Y, Deng T, Liao CW, Tang XL, Chi L (2009) The necessity of building national strain-observation network from the strain abnormality before wenchuan earthquake. Recent Dev World Seismol 1:1-13 (in Chinese with English abstract)

Frank FC (1966) Deduction of earth strains from survey data. Bull Seismol Soc Am 56:35-42

Gladwin MT (1984) High precision multi-component borehole deformation monitoring. Rev Sci Instrum 55:2011-2016

Gladwin MT, Hart R (1985) Design parameters for borehole strain instrumentation. Pure appl Geophys 123:59-80. doi:10.1007/ BF00877049

Hart R, Gladwin MT, Gwyther RL, Agnew DC, Wyatt FK (1996) Tidal calibration of borehole strain meters: removing the effects of small-scale heterogeneity. J Geophys Res 101:25553-25571. doi:10.1029/96JB02273

Hawthorne JC, Rubin AM (2013) Short-time scale correlation between slow slip and tremor in Cascadia. J Geophys Res 118(3):1316-1329

Hodgkinson K, Mencin D, Borsa A, Jackson M (2010) Plate boundary observatory strain recordings of the February 27, 2010, M8.8 Chile Tsunami. Seismol Res Lett 81:3

Ishii H (2001) Development of new multi-component borehole instrument. Report of Tono Research Institute of Earthquake Science 6:5-10 (in Japanese)

Linde AT, Gladwin MT, Johnston M, Gwyther RL, Bilham RG (1996) A slow earthquake sequence on the San Andreas fault. Nature 383:65-68 
Ouyang ZX (1977) RDB-1 type electric capacity strainmeter. Selected Papers of the National Conference on Stress Measurement, Part 2: 337-348 (in Chinese)

Pan LZ (1977) On the formulae of ground stress measurement. Selected Papers of the National Conference on Stress Measurement, Part 1: 1-41 (in Chinese)

Qiu ZH, Chi SL (2013) Shear strains of P wave observed with an YRY-4 borehole strainmeter. Earthquake 33(4):64-70 (in Chinese with English Abstract)

Qiu ZH, Ma J, Chi SL, Liu HM (2007) Earth's free torsional oscillations of the great Sumatra earthquake observed with borehole shear strainmeter. Chin J Geophys 50(3):797-805 (in Chinese with English Abstract)

Qiu ZH, Zhang BH, Chi SL, Tang L, Song M (2011) Abnormal strain changes observed at Guza before the Wenchuan earthquake. Sci China Ser D-Earth Sci 54(2):157-314

Qiu ZH, Tang L, Zhang BH, Guo YP (2013) In situ calibration of and algorithm for strain monitoring using four-gauge borehole strainmeters (FGBS). J Geophys Res 118:1609-1618. doi:10. 1002/jgrb50112
Roeloffs E (2010) Tidal calibration of plate boundary observatory borehole strainmeters: roles of vertical and shear coupling. J Geophys Res 115:B06405. doi:10.1029/2009JB006407

Stein S, Wysession M (2003) An introduction to Seismology, Earthquake, and Earth Structure. Blackwell Publishing, Oxford

Su KZ (1977) Methods of relative measurement of ground stress. In: Selected Papers of the National Conference on Stress Measurement, Part 1: 42-61 (in Chinese)

Timoshenko S, Goodier JN (1951) Theory of Elasticity, 2nd edn. McGraw-Hill, New York

Voight B, Hidayat D, Sacks S, Linde A, Chardot L, Clarke A, Elsworth D, Foroozan R, Malin P, Mattioli G, McWhorter N, Shalev E, Sparks RSJ, Widiwijayanti C, Young SR (2010) Unique strainmeter observations of Vulcanian explosions, Soufrière Hills Volcano, Montserrat, July 2003. Geophys Res Lett 37:L00E18. doi:10.1029/2010GL042551

Wang K, Dragert H, Kao H, Roeloffs E (2008) Characterizing an "uncharacteristic" ETS event in northern Cascadia. Geophys Res Lett 35:L15303. doi:10.1029/2008GL034415 